\title{
Influence of biochar additions on the fracture behavior of foamed concrete
}

\author{
Devid Falliano, Dario De Domenico, Antonino Sciarrone, Giuseppe Ricciardi \\ University of Messina, Italy \\ dfalliano@unime.it, bttp://orcid.org/0000-0001-6676-9187 \\ dario.dedomenico@unime.it, bttp:/ /orcid.org/0000-0003-1279-9529
}

Luciana Restuccia, Giuseppe Ferro, Jean-Marc Tulliani

Politecnico di Torino, Italy

luciana.restuccia@polito.it, http://orcid.org/0000-0002-6999-0466

ferro@polito.it, bttp://orcid.org/0000-0002-0622-4203

Ernesto Gugliandolo

G. Gugliandolo s.r.l., Messina, Italy

ernestogugliandolo@botmail.com

\begin{abstract}
The present study concerns the experimental investigation of foamed concretes with $1600 \mathrm{~kg} / \mathrm{m}^{3}$ density that incorporate biochar additions in the mix. A series of small notched beams are prepared to determine the fracture energy in CMOD (crack mouth opening displacement) mode and the mechanical properties in terms of flexural and compressive strength. Besides the evaluation of such properties for classical foamed concrete, the influence of the addition of biochar in the lightweight cementitious paste is comparatively investigated. Two different concentrations of biochar are analyzed, namely $2 \%$ and $4 \%$ of the cement weight, and two different curing conditions are studied, namely in air and in water at controlled temperature for 28 days. The results demonstrate that better fracture behavior are obtained with $2 \%$ biochar and air curing conditions. The biochar additions in moderate concentrations (e.g. $2 \%$ ) seems to make the fracture surface more tortuous, thus justifying the numerical outcomes, and does not impair the flexural strength. Further microstructural investigation is underway to confirm the experimental observations. This research paves the way for a promising construction material that is more environmentally friendly and sustainable than traditional materials used in the building industry.
\end{abstract}

KEYWORDS. Foamed concrete; Fracture Energy; Biochar; CMOD; Curing conditions; Lightweight concretes.

\section{OPEN@ACCESS}

Citation: Falliano, D., De Domenico, D., Sciarrone, A., Ricciardi, G., Restuccia, L., Ferro, G., Tulliani, J.M., Gugliandolo, E. Influence of biochar additions on the fracture behavior of foamed concrete, Frattura ed Integrità Strutturale, 51 (2020) 189-198.

Received: 08.11.2019

Accepted: 23.11.2019

Published: 01.01.2020

Copyright: (C) 2020 This is an open access article under the terms of the CC-BY 4.0, which permits unrestricted use, distribution, and reproduction in any medium, provided the original author and source are credited. 


\section{INTRODUCTION}

$\mathrm{I}$ $\mathrm{n}$ the field of lightweight concretes, one of the most promising materials that most effectively achieves thermal insulation, acoustic absorption and fire resistance is foamed concrete [1]-[4]. The ingredients of foamed concrete are water, cement, fine sand, additives (if any) and preformed foam, the latter providing a porous microstructure that is responsible for the lightweight characteristics. The density range that can be obtained with foamed concrete is very wide, from $300 \mathrm{~kg} / \mathrm{m}^{3}$ to $2000 \mathrm{~kg} / \mathrm{m}^{3}$. In particular, foamed concretes with densities up to $1000 \mathrm{~kg} / \mathrm{m}^{3}$ are primarily used to exploit their insulating properties for non-structural applications, while structural elements can be realized with densities exceeding $1400 \mathrm{~kg} / \mathrm{m}^{3}$. Similar to other cementitious materials, in the low-density range foamed concrete has poor mechanical strength. For this reason, different strategies have been proposed in the relevant literature to improve the mechanical strength of foamed concrete at low densities and to limit its brittle behavior, such as addition of fly ash and silica fume [5], introduction of short fibers of different nature [6]-[9] or placement of bi-directional grid reinforcement [10], [11]. Regardless of the reinforcement adopted, the mechanical characteristics of such lightweight cementitious materials is affected by the mix design (water-to-cement ratio, quality and characteristics of the aggregates, etc.) as well as by the quality of the preformed foam and by the nature of the foaming agent used for its generation [12]-[14].

On the other hand, studies dealing with the fracture behavior of foamed concrete are relatively few [15]-[17], and confined to classical foamed concrete. Previous studies by the authors demonstrated that the fracture behavior of foamed concrete is markedly affected by the curing conditions [18], [19], especially at the lower densities. Another interesting aspect concerns the development of enhanced variant of lightweight concretes that incorporate by-products or slags such as electric arc furnace slag [20]-[22] or foundry slag [23], which has motivated the present research work. This paper aims to extend the knowledge on the mechanical characteristics and the fracture behavior of foamed concrete when slags are introduced in the mix design as micro-aggregates. In particular, the foamed concrete variant considered in this contribution is prepared with the addition of biochar, which is the solid waste of the thermochemical conversion of biomass. The choice of the use of biochar derives from previous studies that have shown significant increases in terms of both flexural strength and fracture energy of traditional cement-based composite materials [24]. Moreover, the foamed concrete of this experimental campaign is prepared with a viscosity enhancing agent (VEA) such that the resulting mix has high cohesion and viscosity at the fresh state (green strength), and is termed "extrudable foamed concrete" [2], [10], [25]. As a first step of this experimental campaign, standardized prismatic specimens were prepared and tested according to UNI EN 196-1, in order to determine the optimal process to introduce the biochar particles into the foamed concrete matrix (among three possibilities: mixed with cement, dispersed into the hydration water or dispersed in the pre-formed foam). Once the optimal preparation technique has been established, prismatic notched specimens were prepared and tested according to JCI-S-001 standards, namely three-point bending tests in CMOD (Crack Mouth Opening Displacement) mode, in order to evaluate the fracture energy. These notched specimens, tested at 28 days, were prepared with dry density of $1600 \mathrm{~kg} / \mathrm{m}^{3}$, and different contents of biochar (as percentage with respect to the cement weight) in addition to reference specimens without biochar, and two different curing conditions (water and air). Comparison between specimens with biochar additions against reference specimens has been performed in terms of flexural and compressive strength values, load-CMOD curves, fracture energy and related ductility.

\section{SPECIMEN PREPARATION AND TESTING CONDITIONS}

7 he first step of the experimental campaign is focused on the preparation procedure in relationship to the biochar addition. Indeed, three different introduction modalities are evaluated. In the first modality, the biochar is directly added in the cement at the dry state. After a proper mixing of the powders, water and VEA are added. Once a homogeneous paste is obtained, the preformed foam is finally added in order to achieve a target dry density of $1600 \mathrm{~kg} / \mathrm{m}^{3}$. In the second modality, the biochar is added after the mixing of cement, VEA and water. After obtaining a homogeneous mix including the biochar, the pre-formed foam is finally added as in the first modality. In the third modality, the biochar is mixed with the foam. After generating the pre-formed foam, the biochar is added in the foam and the micro-aggregates are dispersed through a vertical mixer. At this stage, the foam with biochar and the cementitious paste are mixed together. The comparison between the three preparation modalities is made in terms of stability of the mix and density at the fresh state. It has been found that the first two modalities exhibit no significant differences, whereas in the third modality (biochar added in the foam) percentages of biochar $\geq 0.5 \%$ of cement weight lead to an instability of the foam with coalescence phenomena and a resulting material having densities higher than the target dry density (hence higher than the density 
obtained with the other two modalities). In addition, the instability of the foam gives rise to a considerable viscosity loss of the cementitious paste, which is no longer extrudable. Although the biochar directly added in the foam could be more effectively dispersed in the cementitious matrix, the aforementioned results suggest that this preparation modality is not straightforward. Further studies are needed to improve the stability of the foam with biochar percentages $\geq 0.5 \%$. The first preparation modality is finally chosen to facilitate the mixing procedure.

Based on the preparation modality and the established target dry density of $1600 \mathrm{~kg} / \mathrm{m}^{3}$ (corresponding to a fresh density of $1700 \mathrm{~kg} / \mathrm{m}^{3}$ ), a series of small beam specimens are prepared with dimensions $20 \mathrm{x} 20 \mathrm{x} 80 \mathrm{~mm}^{3}$, as shown in Fig. 1 . The specimens are prepared with a Portland CEM I 52.5 R, and a water-to-cement ratio equal to 0.3. The VEA is then added in the paste to improve the cohesion and viscosity at the fresh state, but it does not impair the workability of the mixture. A protein-based foaming agent is used for the foam generation, with a concentration of $5 \%$. The resulting foam has a density of $85 \mathrm{~g} / \mathrm{L}$, and the foam-to-cement ratio (in weight) is 0.08 . More details on the preparation procedures and the mix design can be found in Falliano et al. [12]. Besides the reference specimens without biochar, some specimens are prepared with biochar particles in two different concentrations, namely $2 \%$ and $4 \%$ of cement weight.
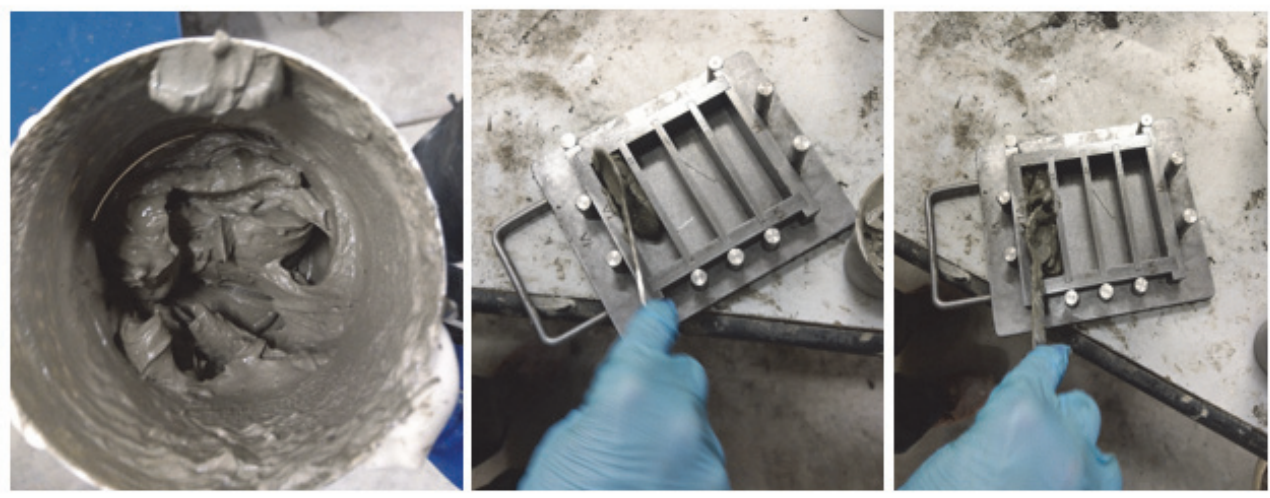

Figure 1: Foamed concrete paste at the fresh state (left) and pouring into formworks for the realization of prismatic beams.
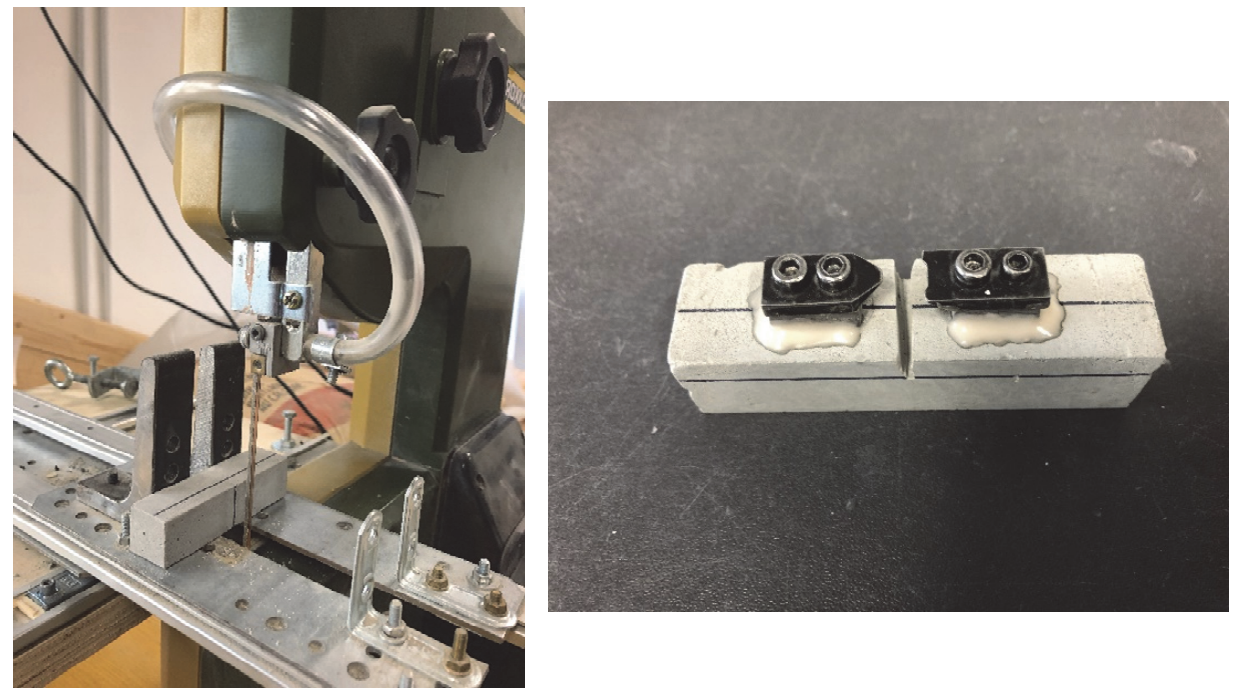

Figure 2: Realization of the notch with band saw (left) and detail on the bonding of the clip-on strain gauge on the two sides of the notch (right)

The beams are kept for 24 hours in formworks, then they are de-molded and left cured for remaining 27 days (overall curing of 28 days). Some specimens are immersed in a water tank at controlled temperature of $20^{\circ} \mathrm{C}$, and some other are cured in air at environmental laboratory conditions (temperature $20 \pm 3^{\circ} \mathrm{C}$ and relative humidity $65-75 \%$ ). In total, 24 specimens are prepared: 8 reference specimens ( 4 cured in air and 4 cured in water), 8 specimens with biochar particles at $2 \%$ concentration ( 4 cured in air and 4 cured in water) and 8 specimens with biochar particles at $4 \%$ concentration ( 4 cured in air and 4 cured in water). After 28 days, the prismatic beams are notched with a band saw (cf. left side of Fig. 2), following the dimensional 
prescriptions of the Japan Concrete Institute Standard JCI-S-001-2003 [26]. In particular, the notch height is set 0.3 D, where $\mathrm{D}$ denotes the height of the beam $(20 \mathrm{~mm})$, and the notch thick $\leq 5 \mathrm{~mm}$.

The tests are performed in displacement controlled mode using a Zwick Line-Z010 testing equipment [27]-[29] having a 1 $\mathrm{kN}$ load capacity. A clip-on strain gauge is installed at the two sides of the notch to measure the CMOD (cf. right side of Fig. 2). A displacement rate of $0.005 \mathrm{~mm} / \mathrm{min}$ is used, and the beam span is adjusted to $70 \mathrm{~mm}$. At the end of the flexural tests, the two halves of the broken prism are tested in compression in another testing equipment with load capacity of 50 $\mathrm{kN}$ and displacement rate of $0.5 \mathrm{~mm} / \mathrm{min}$. Details of the testing equipment used for both the flexural tests and the compression tests are shown in Fig. 3.
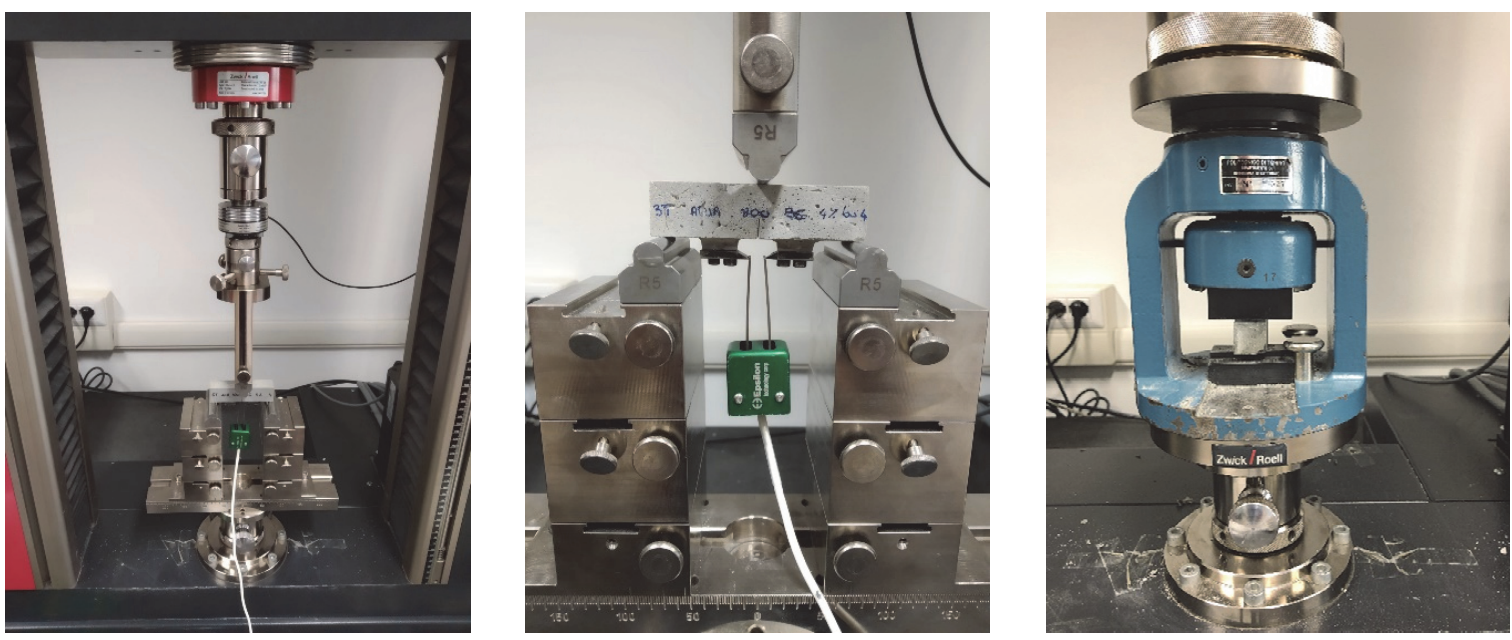

Figure 3: Flexural tests with CMOD measurements on notched prisms (left), detail of the clip-on strain gauge (centre) and compression test on halves of the broken prism (right)

\section{RESULTS AND DISCUSSION}

he results of the experimental campaign consist of flexural strength, compressive strength and fracture energy. The flexural strength is calculated according to the following expression:

$$
\sigma_{f}=\frac{3}{2} \frac{F_{\max } L}{b b^{2}}
$$

where $F_{\max }$ represents the maximum load, $L$ is the span length of the specimen, $b$ is the specimen depth $(20 \mathrm{~mm})$ and $b$ the net ligament height. Moreover, the fracture energy $G_{F}$ is computed through the formula reported in JCI-S-001 [26]:

$$
G_{F}=\frac{0.75 W_{0}+W_{1}}{A_{\text {lig }}}
$$

where $A_{\text {lig }}$ indicates the area of nominal ligament, $W_{0}$ denotes the area below the CMOD curve up to rupture of specimen and $W_{1}$ is the work done by the self-weight and the applied loading, the latter being computed as follows:

$$
W_{1}=0.75\left(\frac{\ell}{L} m_{1} g+2 m_{2} g\right) \mathrm{CMOD}_{c}
$$

where $L$ is the entire length of the specimen, $m_{1}$ is the mass of the notched specimen, $m_{2}$ indicates the mass of the loading arrangement part not attached to the testing machine but placed on beam until rupture, $g$ is the acceleration of gravity and $\mathrm{CMOD}_{\mathrm{c}}$ is the crack mouth opening displacement at the rupture. This calculation procedure of the JCI-S-001 [26] is consistent with the RILEM procedure to determine the fracture energy. Other methods are present in the relevant literature, 
such as the two-parameter model proposed by Shah and coworker [30]. According to the latter method, the geometrical dimensions of the samples are crucial in the determination of the stress intensity factor, especially for cement pastes that are more notch-sensitive than concrete samples [31]. The comparison between the two calculation methods will be further investigated in future work.

The main results of the experimental tests are listed in Tab. 1 in terms of flexural strength, fracture energy and compressive strength (the latter determined as mean value of the two halves of the broken prism). It is seen that the flexural strength is affected by the curing conditions: indeed, the mean flexural strength of water-cured specimens is around $30 \%$ lower than that of the corresponding air-cured ones. This is also confirmed by other studies in the literature concerning foamed concrete at lower densities [18], in which it was shown that the curing conditions affect the hydration process and the microstructural configuration of the cementitious paste. With regard to the influence of the biochar on the flexural strength, it is noted that the addition of $2 \%$ contents does not alter the flexural strength, while higher contents (4\%) contribute to a modest decrease of the flexural strength (approximately 10\% in comparison with original specimens without biochar for air curing conditions). Instead, for water curing conditions, the presence of the biochar implies a marked decrease of the flexural strength in either concentration $(2 \%$ and $4 \%)$. A comparative histogram of all flexural strength values is plotted in Fig. 4.

\begin{tabular}{cccc}
\hline \multirow{2}{*}{ Specimen class } & Flexural strength & Fracture energy & Compressive strength \\
\cline { 2 - 4 } & $\sigma_{f}[\mathrm{MPa}]$ & $G_{F}[\mathrm{~N} / \mathrm{m}]$ & $\sigma_{c}[\mathrm{MPa}]$ \\
\hline No biochar air curing & 3.28 & 21.81 & 48.35 \\
No biochar water curing & 2.40 & 27.67 & 47.38 \\
Biochar 2\% air curing & 3.22 & 23.90 & 26.92 \\
Biochar 2\% water curing & 2.38 & 11.76 & 28.99 \\
Biochar 4\% air curing & 2.96 & 20.85 & 25.75 \\
Biochar 4\% water curing & 2.06 & 22.62 & 25.02 \\
\hline
\end{tabular}

Table 1: Experimental results of analyzed specimens with different curing conditions and biochar contents.

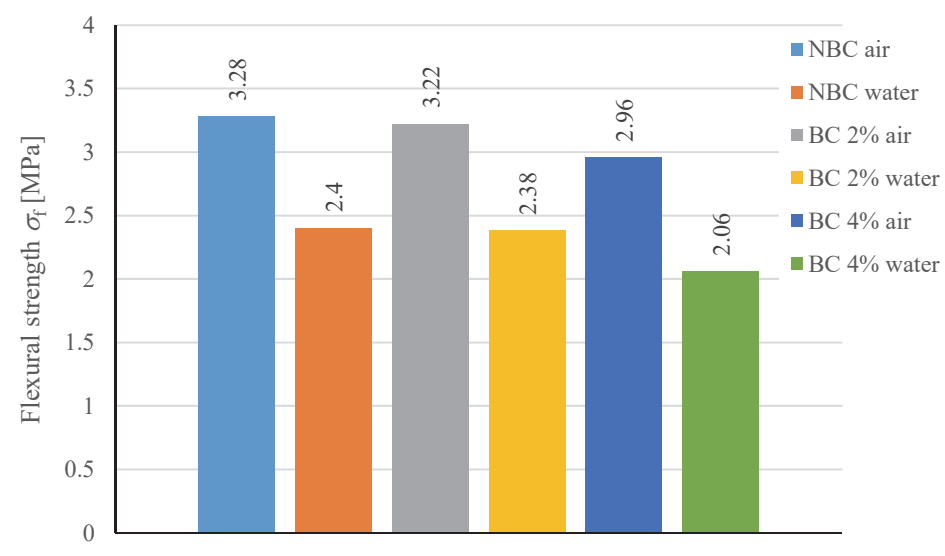

Figure 4: Comparative histograms of average flexural strength of foamed concrete specimens with different curing conditions and biochar contents.

With regard to the fracture energy, it is noted that the curing conditions do not lead to a marked difference of results for $4 \%$ biochar contents as can be seen in the comparative histogram of Fig. 5 . Indeed, while the flexural strength of watercured specimens is lower than that of air-cured ones, the overall ductility (deformation capacity in the post-elastic branch) is much greater in the water curing conditions as can be seen in the Force-CMOD curves shown in the right side of Fig. 6. Therefore, the fracture energy in the two cases turns out to be of comparable order. It is worth noting that in the case of biochar content of $2 \%$ some unexpected fracture energy values were obtained for specimens cured in water (around 50\% 
lower than the analogous specimens cured in air). This seems to be related to a premature damage occurred in the tested specimens and to a non-perfect alignment of the loading apparatus for this limited class of specimens. The addition of biochar at $4 \%$ concentration worsens the fracture energy performance, while lower concentrations seem to be beneficial in improving the fracture behavior for the air curing conditions. The different fracture energy values for specimens with biochar at $2 \%$ concentration in the two different curing conditions can be explained by a macroscopic observation of the fracture surface. Fig. 7 illustrates that the fracture surface for air curing is more tortuous than the analogous fracture surface for water curing. When comparing these results with those in Fig. 8 (specimens with $4 \%$ biochar concentration) it is noted that for air curing conditions the specimen with $2 \%$ biochar have a more tortuous fracture surface that the specimen with $4 \%$ biochar, thus qualitatively justifying the obtained results. Moreover, by comparing the specimens without biochar and with $2 \%$ biochar in air curing conditions, it is noted that the addition of biochar increases the fracture energy (in line with previous studies from the literature in ordinary concretes [24]). This result is justified in view of the further modifications of the fracture path provided by the biochar additions in the foamed concrete microstructure and in view of the fact that, unlike biochar at $4 \%$ concentrations, the presence of the micro-aggregates does not produce a decrease of the flexural strength.

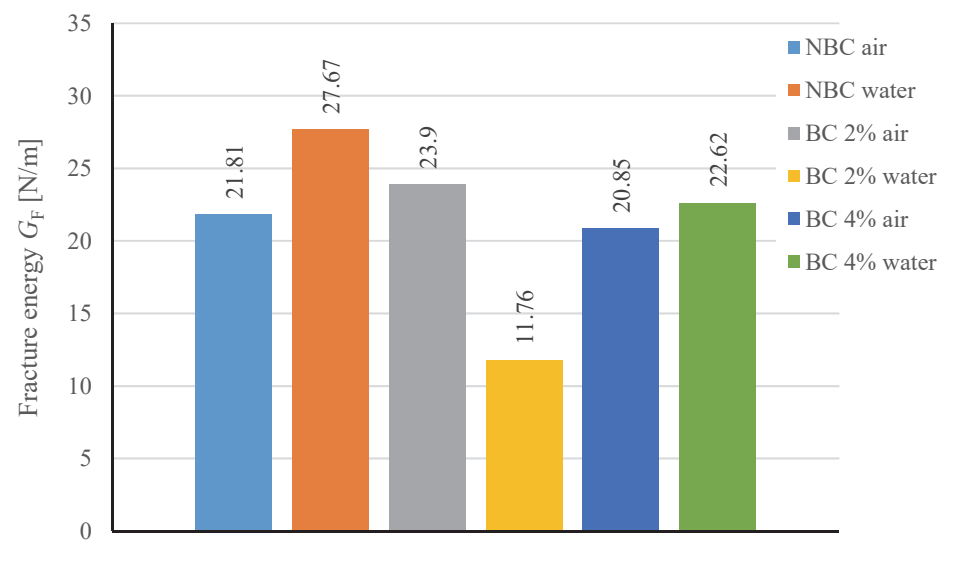

Figure 5: Comparative histograms of average fracture energy of foamed concrete specimens with different curing conditions and biochar contents.
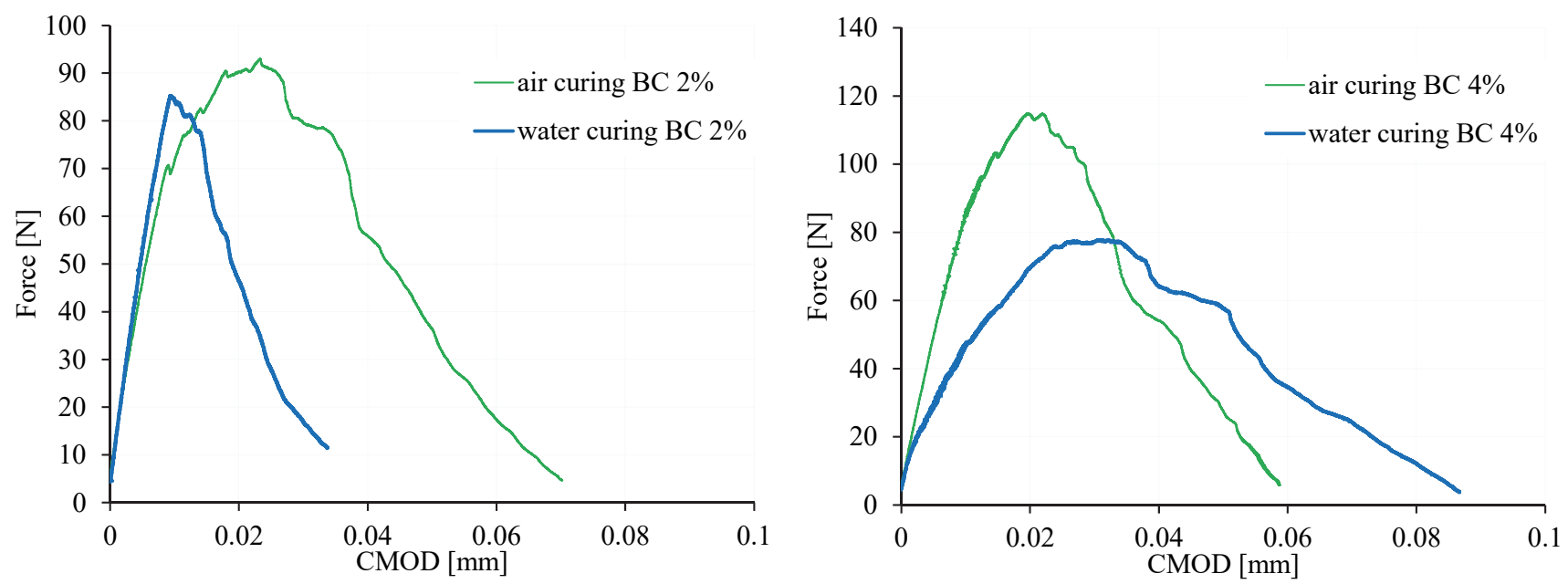

Figure 6: Force displacement curves of foamed concrete specimens with different curing conditions and biochar content of $2 \%$ (left) and $4 \%$ (right) of the cement weight

There is a change of trend between the flexural strength and fracture energy in the two curing conditions for samples without biochar. Indeed, for this class of specimens, the flexural strength is higher for air curing conditions than for water curing conditions, whereas the fracture energy is higher in the water curing conditions. This is due to a different behavior in the post-elastic branch of the two classes of specimens (water-cured and air-cured). As previously highlighted for specimens 
with $4 \%$ biochar, the post-elastic branch of the Force-CMOD curve of specimens cured in water without biochar is more pronounced and directly affects the value of the fracture energy, despite the associated lower peak load.
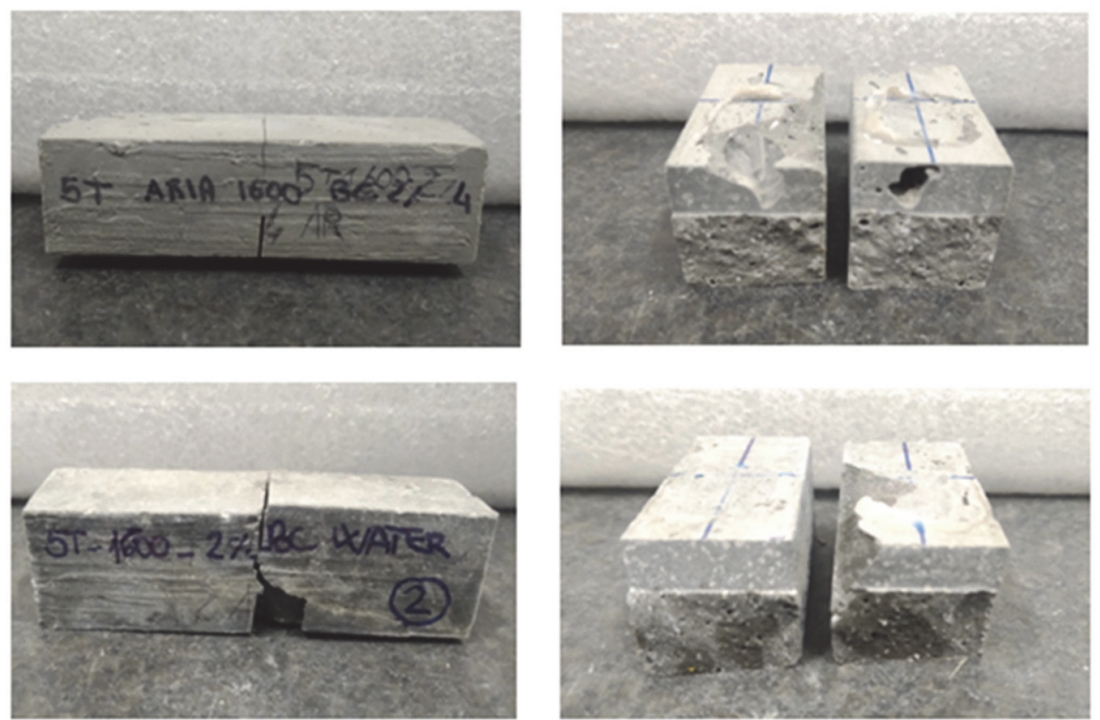

Figure 7: Fracture path and fracture surface of four analyzed foamed concrete notched beams with $2 \%$ biochar cured in air (top) and in water (bottom).
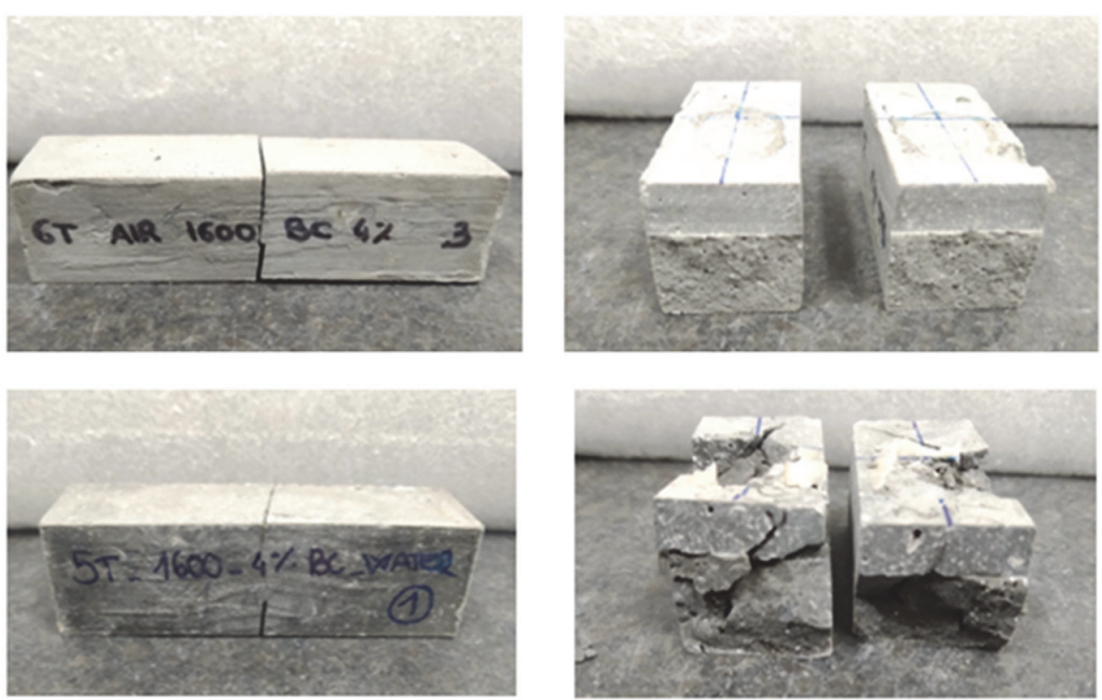

Figure 8: Fracture path and fracture surface of four analyzed foamed concrete notched beams with 4\% biochar cured in air (top) and in water (bottom).

Finally, the results in terms of compressive strength are shown in Fig. 9. It is seen that the curing conditions do not markedly affect the compressive strength values in all the analyzed specimens (without biochar, with $2 \%$ biochar and $4 \%$ biochar concentration). The foamed concrete specimens without biochar have a mean compressive strength of around $48 \mathrm{MPa}$ while the addition of biochar implies a significant reduction of the compressive strength even of almost $50 \%$. These results point out that in the field of foamed concretes in the medium-to-high density range, the addition of biochar with concentrations higher than $2 \%$ reduce the compressive strength in a considerable manner. This is confirmed by previous studies from the literature regarding ordinary concretes with biochar [24]. Although the previous studies refer to ordinary concrete (not foamed), considering the high-density range of the foamed concrete analyzed in the present study, the authors believe that these results are consistent with previous investigations in the field. Nevertheless, the increase of flexural strength and fracture energy accomplished by biochar contents of $2 \%$ compensates for the decrease of compressive strength, 
which is still higher than $25 \mathrm{MPa}$ (thus guaranteeing the feasibility of structural applications). Overall, the use of biochar decreases the cement amount in the preparation of the foamed concrete, thereby leading to a material that exploits recycled components and, hence, that converts a slag material (biochar) into a useful resource.

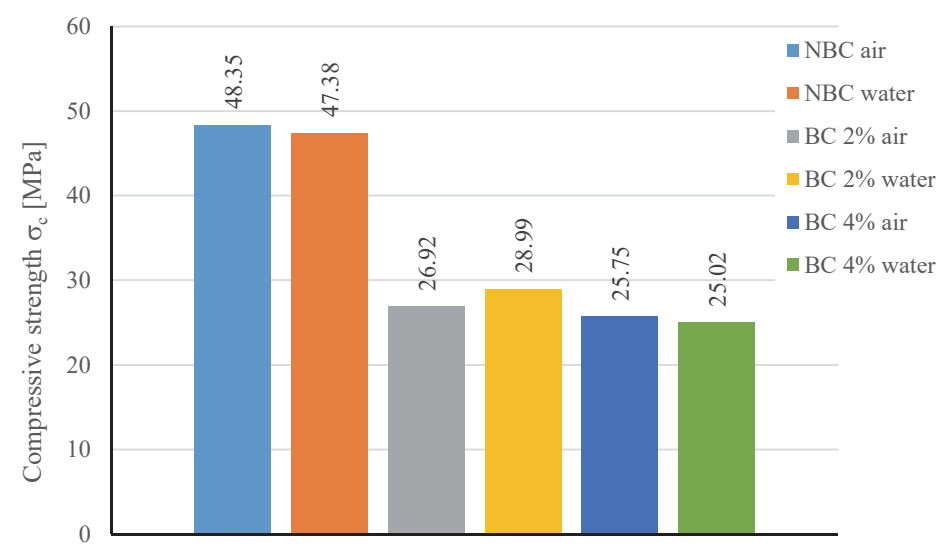

Figure 9: Comparative histograms of average compressive strength of foamed concrete specimens with different curing conditions and biochar contents.

\section{CONCLUSIONS}

7 his study has investigated the fracture properties and the mechanical strengths of foamed concrete with and without biochar additions at a target dry density of $1600 \mathrm{~kg} / \mathrm{m}^{3}$. It has been found that the most appropriate method for the addition of biochar during the foamed concrete preparation is to mix it with cement at the dry state. It has been found that introducing biochar in the foam may cause instability, coalescence phenomena and collapse of the threedimensional structure of the foam before the mixing phase. Two different curing conditions were compared, namely specimens cured in air and in water at controlled temperature for 28 days. Moreover, two different biochar concentrations of $2 \%$ and $4 \%$ in cement weight were analyzed. In order to analyze the fracture behavior, notched beam specimens are prepared and tested in CMOD mode with a clip-on strain gauge to control the crack opening. The fracture energy has been assessed based on the Japanese standards JCI-S-001. Moreover, besides the flexural strength calculated in the three-point bending tests, the compressive strength values were determined in the two resulting halves of the broken prism. The results have demonstrated that the foamed concrete without biochar is markedly affected by the curing conditions: specimens cured in air have a higher flexural strength (of around 30\%) than those cured in water; however, the fracture energy of air-cured specimens is lower than those of water-cured ones, because the Force-CMOD curve of the formed class is characterized by lower ductility than the latter. The compressive strengths are higher than $45 \mathrm{MPa}$, thus making it feasible to use this material even for structural applications. With regard to the influence of biochar additions, it has been found that the $2 \%$ biochar contents led to improvements in terms of fracture energy in air curing conditions, while the flexural strength is almost identical to the case of specimens without biochar. The other combinations of biochar contents and/or curing conditions yielded worsening of the behavior of all the mechanical properties investigated. In particular, in all cases the compressive strength is negatively influenced by the presence of biochar. Nevertheless, considering the advantages of the biochar additions (lower environmental impact, lower amount of raw materials, recycling of a slag component) and considering the values of the resulting compressive strength higher than $25 \mathrm{MPa}$, the development of biochar-based foamed concretes seems to be an attractive line of research and deserves further investigation at different densities.

\section{REFERENCES}

[1] Wei, S., Yiqiang, C., Yunsheng, Z., Jones, M.R. (2013). Characterization and simulation of microstructure and thermal properties of foamed concrete. Construction and Building Materials, 47, pp. 1278-1291, DOI: 10.1016/j.conbuildmat.2013.06.027. 
[2] Falliano, D., Gugliandolo, E., De Domenico, D., Ricciardi, G. (2019). Experimental Investigation on the Mechanical Strength and Thermal Conductivity of Extrudable Foamed Concrete and Preliminary Views on Its Potential Application in 3D Printed Multilayer Insulating Panels. In: First RILEM International Conference on Concrete and Digital Fabrication - Digital Concrete 2018, Springer, Cham, pp. 277-286, DOI: 10.1007/978-3-319-99519-9_26.

[3] Valore, R.C. (1954). Cellular concrete part 2 physical properties. ACI J, 50, pp. 817-836.

[4] Kim, H.K., Jeon, J.H., Lee, H.K. (2012). Workability, and mechanical, acoustic and thermal properties of lightweight aggregate concrete with a high volume of entrained air. Construction and Building Materials, 29, pp. 193-200, DOI: 10.1016/j.conbuildmat.2011.08.067.

[5] Jones, M.R., McCarthy, A. (2005). Preliminary views on the potential of foamed concrete as a structural material. Magazine of concrete research, 57(1), pp. 21-31, DOI: 10.1680/macr.2005.57.1.21.

[6] Falliano, D., De Domenico, D., Ricciardi, G., Gugliandolo, E. (2019). Compressive and flexural strength of fiberreinforced foamed concrete: Effect of fiber content, curing conditions and dry density. Construction and Building Materials, 198, pp. 479-493, DOI: 10.1016/j.conbuildmat.2018.11.197.

[7] Bing, C., Zhen, W., Ning, L. (2011). Experimental research on properties of high-strength foamed concrete. Journal of Materials in Civil Engineering, 24(1), pp. 113-118, DOI: 10.1061/(ASCE)MT.1943-5533.0000353.

[8] Kayali, O., Haque, M.N., Zhu, B. (2003). Some characteristics of high strength fiber reinforced lightweight aggregate concrete. Cement and Concrete Composites, 25(2), pp. 207-213, DOI: 10.1016/S0958-9465(02)00016-1.

[9] Ramamurthy, K., Nambiar, E.K., Ranjani, G.I.S. (2009). A classification of studies on properties of foam concrete. Cement and Concrete Composites, 31(6), pp. 388-396; DOI: 10.1016/j.cemconcomp.2009.04.006.

[10] Falliano, D., De Domenico, D., Ricciardi, G., Gugliandolo, E. (2019). Improving the flexural capacity of extrudable foamed concrete with glass-fiber bi-directional grid reinforcement: An experimental study. Composite Structures, 209, pp. 45-59, DOI: 10.1016/j.compstruct.2018.10.092.

[11] Falliano, D., Sciarrone, A., De Domenico, D., Maugeri, N., Longo, P., Gugliandolo, E., Ricciardi, G. (2019). Fiberreinforced lightweight foamed concrete panels suitable for $3 \mathrm{D}$ printing applications. In IOP Conference Series: Materials Science and Engineering, 615(1), pp. 012018, DOI: 10.1088/1757-899X/615/1/012018.

[12] Falliano, D., De Domenico, D., Ricciardi, G., Gugliandolo, E. (2018). Experimental investigation on the compressive strength of foamed concrete: Effect of curing conditions, cement type, foaming agent and dry density. Construction and Building Materials, 165, pp. 735-749, DOI: 10.1016/j.conbuildmat.2017.12.241.

[13] Panesar, D.K. (2013). Cellular concrete properties and the effect of synthetic and protein foaming agents. Construction and Building Materials, 44, pp. 575-584, DOI: 10.1016/j.conbuildmat.2013.03.024.

[14] Falliano, D., De Domenico, D., Ricciardi, G., Gugliandolo, E. (2018). Key factors affecting the compressive strength of foamed concrete. In IOP Conference Series: Materials Science and Engineering, 431(6), p. 062009, IOP Publishing, DOI: $10.1088 / 1757-899 \mathrm{X} / 431 / 6 / 062009$.

[15] Hengst, R.R., Tressler, R.E. (1983). Fracture of foamed Portland cements. Cement and Concrete Research, 13(1), pp. 127-134, DOI: 10.1016/0008-8846(83)90136-9.

[16] Kozłowski, M., Kadela, M., Kukiełka, A. (2015). Fracture energy of foamed concrete based on three-point bending test on notched beams. Procedia Engineering, 108, 349-354, DOI: 10.1016/j.proeng.2015.06.157.

[17] Kozłowski, M., Kadela, M. (2018). Combined Experimental and Numerical Study on Fracture Behaviour of LowDensity Foamed Concrete. In IOP Conference Series: Materials Science and Engineering; 324(1), p. 012031. IOP Publishing, DOI: 10.1088/1757-899X/324/1/012031.

[18] Falliano, D., De Domenico, D., Sciarrone, A., Ricciardi, G., Restuccia, L., Tulliani, J. M. C., Gugliandolo, E. (2019). Fracture behavior of lightweight foamed concrete: the crucial role of curing conditions. Theoretical and Applied Fracture Mechanics, 103, pp. 102297, DOI: 10.1016/j.tafmec.2019.102297.

[19] Falliano, D., De Domenico, D., Sciarrone, A., Ricciardi, G., Restuccia, L., Ferro, G., Tulliani, J. M. C., Gugliandolo, E. (2019). Investigation on the fracture behavior of foamed concrete. Procedia Structural Integrity, 18, pp. 525-531, DOI: $10.1016 /$ j.prostr.2019.08.196.

[20] Faleschini, F., Zanini, M. A., Toska, K. (2019). Seismic reliability assessment of code-conforming reinforced concrete buildings made with electric arc furnace slag aggregates. Engineering Structures, 195, pp. 324-339.

[21] Faleschini, F., Bragolusi, P., Zanini, M. A., Zampieri, P., Pellegrino, C. (2017). Experimental and numerical investigation on the cyclic behavior of RC beam column joints with EAF slag concrete. Engineering Structures, 152, pp. 335-347.

[22] De Domenico, D., Faleschini, F., Pellegrino, C., \& Ricciardi, G. (2018). Structural behavior of RC beams containing EAF slag as recycled aggregate: Numerical versus experimental results. Construction and Building Materials, 171, pp321-337. 
[23]Jones, M. R., McCarthy, A., \& Dhir, R. K. (2005). Recycled and secondary aggregate in foamed concrete WRAP Research report, the waste and resources action programme. Banbury, Oxon OX16 0AH.

[24] Restuccia, L., Ferro, G.A. (2016). Promising low cost carbon-based materials to improve strength and toughness in cement composites. Constr. Build. Mater., 126, pp. 1034-1043, DOI: 10.1016/j.conbuildmat.2016.09.101.

[25] Falliano, D., De Domenico, D., Ricciardi, G., Gugliandolo, E. (2018). Mechanical characterization of extrudable foamed concrete: an experimental study. World Academy of Science, Engineering and Technology International Journal of Civil and Environmental Engineering, 12, pp. 228-232.

[26] JCI-S-001. (2003). Method of Test for Fracture Energy of Concrete by use of Notched Beam, Japan Concrete Institute, Tokyo, Japan.

[27] Ahmad, S., Tulliani, J.M., Ferro, G.A., Khushnood, R.A., Restuccia, L., Jagdale, P. (2015). Crack path \& fracture surface modifications in enhanced cement composites. Frattura ed Integrità Strutturale, 34, pp. 524-533, DOI: $10.3221 /$ IGF-ESIS.34.58.

[28] Restuccia, L., Reggio, A., Ferro, G.A., Kamranirad, R. (2017). Fractal analysis of crack paths into innovative carbonbased cementitious composites. Theoretical and Applied Fracture Mechanics, 90, pp. 133-141, DOI: $10.1016 /$ j.tafmec.2017.03.016.

[29] Restuccia, L., Ferro, G.A. (2018). Influence of filler size on the mechanical properties of cement-based composites. Fatigue and Fracture of Engineering Materials and Structures, 41(4), pp. 797-805, DOI: 10.1111/ffe.12694.

[30] Jenq, Y., Shah, S.P. (1985). Two parameter fracture model for concrete. J Eng Mech, 111(10), pp. 1227-1241, DOI: 10.1061/(ASCE)0733-9399(1985)111:10(1227).

[31] Shah, S.P., McGarry, F.J. (1985). Griffith Fracture Criterion and Concrete. J Eng Mech, 97(6), pp. 1663-1675. 